\title{
Tumor cell-derived PDGF-B potentiates mouse mesenchymal stem cells-pericytes transition and recruitment through an interaction with NRP-1
}

\author{
Kakali Dhar ${ }^{1,2}$, Gopal Dhar ${ }^{1,2}$, Monami Majumder ${ }^{1,2}$, Inamul Haque ${ }^{1,2}$, Smita Mehta ${ }^{1,2}$, Peter J Van Veldhuizen ${ }^{1,2}$, \\ Sushanta K Banerjee ${ }^{1,2,3^{*}}$, Snigdha Banerjee ${ }^{1,2^{*}}$
}

\begin{abstract}
Background: New blood vessel formation, or angiogenic switch, is an essential event in the development of solid tumors and their metastatic growth. Tumor blood vessel formation and remodeling is a complex and multi-step processes. The differentiation and recruitment of mural cells including vascular smooth muscle cells and pericytes are essential steps in tumor angiogenesis. However, the role of tumor cells in differentiation and recruitment of mural cells has not yet been fully elucidated. This study focuses on the role of human tumor cells in governing the differentiation of mouse mesenchymal stem cells (MSCs) to pericytes and their recruitment in the tumor angiogenesis process.

Results: We show that $\mathrm{C} 3 \mathrm{H} / 10 \mathrm{~T} 1 / 2$ mouse embryonic mesenchymal stem cells, under the influence of different tumor cell-derived conditioned media, differentiate into mature pericytes. These differentiated pericytes, in turn, are recruited to bind with capillary-like networks formed by endothelial cells on the matrigel under in vitro conditions and recruited to bind with blood vessels on gel-foam under in vivo conditions. The degree of recruitment of pericytes into in vitro neo-angiogenesis is tumor cell phenotype specific. Interestingly, invasive cells recruit less pericytes as compared to non-invasive cells. We identified tumor cell-secreted platelet-derived growth factor-B (PDGF-B) as a crucial factor controlling the differentiation and recruitment processes through an interaction with neuropilin-1 (NRP-1) in mesenchymal stem cells.

Conclusion: These new insights into the roles of tumor cell-secreted PDGF-B-NRP-1 signaling in MSCs-fate determination may help to develop new antiangiogenic strategies to prevent the tumor growth and metastasis and result in more effective cancer therapies.
\end{abstract}

\section{Background}

Tumor cells assign neighboring blood vessels to support their own blood supply for oxygen and nutrients and finally for intravasation (to enter into the blood vessels) and extravasation (metastatic spread) through promoting pathologic neovascularization/angiogenesis [1-3]. This event is potentiated by tumor cells through the production of diffusible angiogenic factors [4-6]. New blood vessel formation/angiogenesis and remodeling of the vessel is a complex event and is dependent on proliferation, differentiation, mobilization and attachment of

\footnotetext{
* Correspondence: sbanerjee2@kumc.edu; sbanerjee@kumc.edu ${ }^{1}$ Cancer Research Unit, VA Medical Center, 4801 Linwood Blvd, Kansas City,
} Missouri 6 4128, USA

(C) 2010 Dhar et al; licensee BioMed Central Ltd. This is an Open Access article distributed under the terms of the Creative Commons Attribution License (http://creativecommons.org/licenses/by/2.0), which permits unrestricted use, distribution, and reproduction in any medium, provided the original work is properly cited. endothelial cells (ECs) and mural cells (MCs) with different phenotypic variants such vascular smooth muscle cells (VSMCs) and pericytes (PCs) in an autocrine-paracrine manner [7-11]. The literature on the molecular interactions of tumor cells with ECs for the angiogenic switch is appreciable, but less is known about mural cells.

VSMCs/PCs, which are located in different vascular systems according to their needs [11], play critical roles in both normal and pathologic vascular development, integrity and its maintenance [11-14]. Although VSMCs and PCs are morphologically similar, and express common molecular markers, they may function differently [11]. The vascular SMCs provide structural support to the large vessels and are critical regulators of blood 
flow, while PCs appear to be involved in the early events of capillary sprouting. The PCs are regularly found lying at and in front of the advancing tips of endothelial sprouts and may serve as a guiding structure of endothelial outgrowth $[11,12]$ and termination of the event [13]. PCs are irregular in shape in tumors and loosely associated with ECs on tumor vessels $[15,16]$, During new blood vessel formation and assembly, recruitment of PCs through the differentiation of precursor cells (mesenchymal), migration and attachment to the newly formed capillaries are vital events of this multistep process $[17,18]$. However, the role(s) of tumor cells in differentiation, recruitments and attachment of these cells are still under described. Therefore, we are interested to explore whether the tumor cells have the ability to differentiate, recruit and interact with PCs to establish new blood vessels for their maintenance.

Accumulated evidences have shown that both endothelial and non-endothelial cells recruit pericytes in tumor blood vessels through PDGF-B, its receptor (PDGF-R $\beta$ ) and VEGF signaling networks in a mouse fibrosarcoma model and in U87MG glioma model $[18,19]$. Recently, our studies have found that breast tumor cells are capable of modulating the migration of vascular SMCs in vitro, and this event is mediated through vascular endothelial growth factor (VEGF)/B-form of plateletderivative growth factor (PDGF-B) - neuropilin-1 (NRP$1)$ signaling pathways $[20,21]$. This study, for the first time to our knowledge, shed light on the molecular interactions of tumor cells with mesenchymal stem cells, and offers new opportunities to improve the understanding of the regulation of pathologic pericytes by cell-cell interactions through successive studies. The main objective of the present work is to extend our initial findings and test the hypothesis that the interaction of tumor cells with mural precursor cells may cause differentiation of precursor cells to PCs (mesenchymal to pericyte transition) and the recruitment/attachment for tumor angiogenesis.

To test this concept, we determined whether different tumor cell-derived conditioned media are able to differentiate and recruit the mesenchymal stem cells to pericytes. We demonstrate that the tumor cell-derived conditioned media are capable of differentiating the stem cells to PCs; ultimately recruiting them to bind with endothelial cells differentially. The studies also reveal that tumor cell-secreted PDGF is the responsible molecule for differentiation as well as for recruitment through a physical interaction with NRP-1.

\section{Results}

Tumor cell-derived conditioned media (TCM) enhance the proliferation of mesenchymal stem cells

For new blood vessel formation, mesenchymal stem cells need to proliferate. In this experiment, we determined whether tumor cell-derived diffusible factors in the conditioned media are able to increase the mesenchymal stem cell's proliferation rate. To test this, C3H/10T1/2 mouse mesenchymal stem cells were used for this study. These cells were isolated from $\mathrm{C} 3 \mathrm{H}$ mouse embryo pluripotent stem cells and considered as mesenchymal cells because they have the ability to differentiate into a variety of mesodermal cell lineages [22]. Our studies are in agreement with previous findings and indicate that this embryonic cell line is the mesenchymal type. The immuno-Western blot analysis showed that epithelial marker proteins (i.e., E-Cadherin, Keratin 19, Beta-catenin) are absent in these cells while mesenchymal marker, vimentin, is overexpressed (Fig. 1A). Moreover, mural cell markers are either absent or minimally expressed in $10 \mathrm{~T} 1 / 2$ cells (Fig. $1 \mathrm{~B}$ and $1 \mathrm{C}$ ). These include $\alpha$-SMA, calponin and desmin. After confirmation of the stem cell behavior, $10 \mathrm{~T} 1 / 2$ cells $(60 \%$ confluent) were incubated with different TCM for 24 hours. Cells were trypsinized and stained with trypan blue for the count in Cellometer Auto T4 (Nexcelom Bioscience, Lawrence, MA 01843). We found that the cell number of the conditioned media incubated $10 \mathrm{~T} 1 / 2$ cells increased more significantly than the control, and maximum cell number was increased in the invasive (MDAMB-231 and PaCa-2) cell line-derived-CM in comparison to the non-invasive (MCF-7) cell line-derived CM (Fig. 1D). In order to confirm whether the induction of cell number was due to the proliferation or inhibition of apoptosis, we determined the apoptosis using cell death ELISA assay. No significant apoptotic cell death was observed in TCM exposed and unexposed cells (data not shown). Collectively, these studies indicate that TCM induced induction of cell numbers is due to the stimulation of cellular proliferation.

\section{TCM is able to differentiate the mesenchymal stem cells to pericytes}

The communication between tumor cells and surrounding stroma is a well established phenomenon and this event is very crucial for tumor growth [23-26]. However, tumor cell-induced mesenchymal stem cell (MSC) transition to pericytes and their attachment in contribution to neovascularization has not yet been fully elucidated. Therefore, we investigated whether human tumor cells are able to force the mouse MSC to differentiate to pericytes (PCs). To do so, semi-confluent 10T1/2 MSC were incubated with $10 \mathrm{~T} 1 / 2$ media (RM), or different tumor cell (MIA-PaCa-2, MCF-7 and MDA-MB-231)-derived conditioned media (TCM) for 24 and $72 \mathrm{~h}$ and fixed and processed for immunofluroscent staining with alpha smooth muscle actin ( $\alpha$-SMA), a positive marker of mural cells [11]. As shown in Fig. 2, $\alpha$-SMA antibody weakly immuno-reacts with RM-exposed cells as 


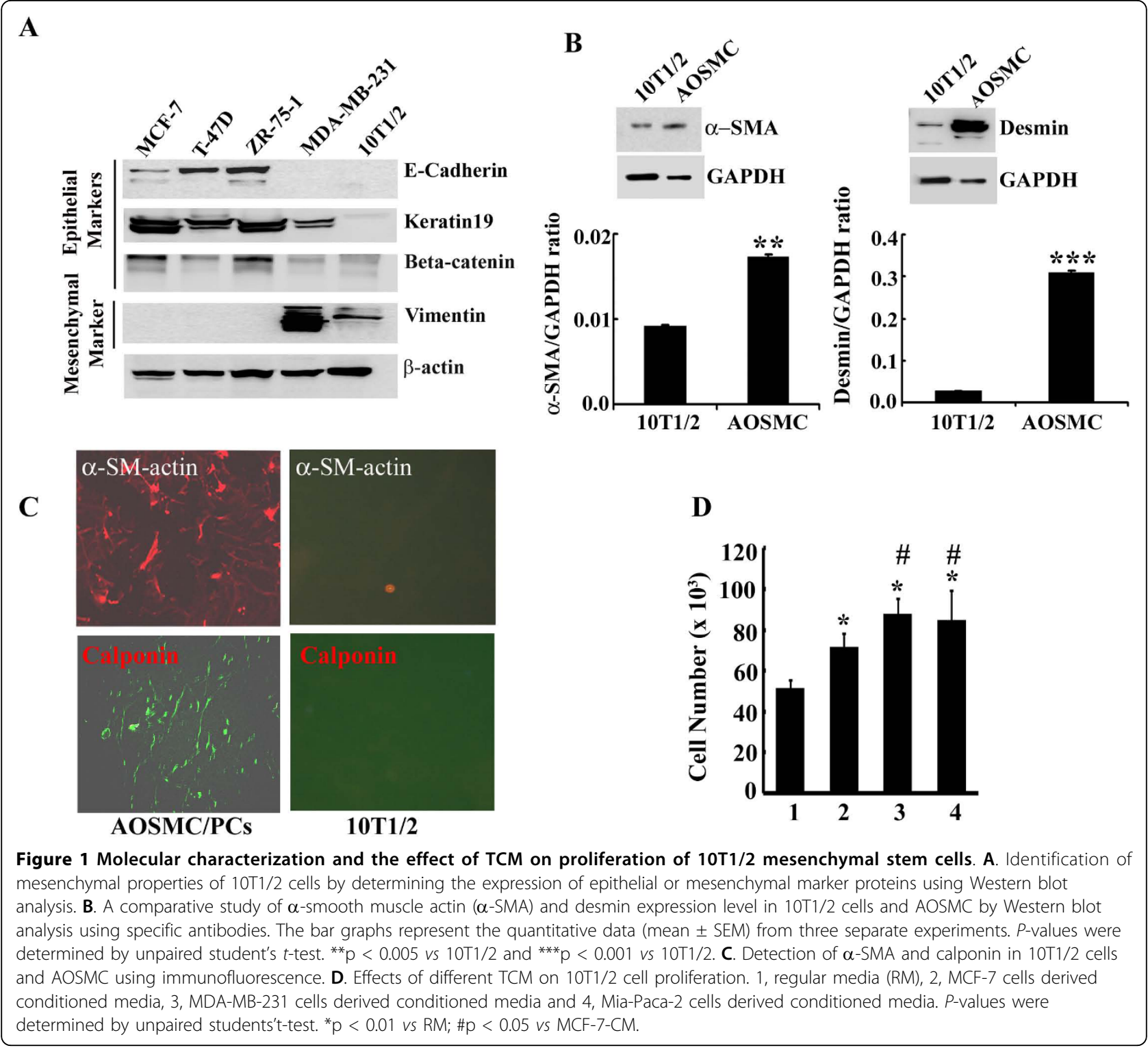

compared to TCM-exposed cells. In TCM-exposed cells, reactions were increased in time dependent fashion. Furthermore, we found that the staining intensity of $\alpha$ SMA was reliant on the aggressiveness of the tumor cells. For example, MCF-7 non-invasive breast tumor cell-derived CM moderately enhanced $\alpha$-SMA expression in $10 \mathrm{~T} 1 / 2$ cells, while its expression was very strong in invasive cells (MDA-MB-231 and MIA PaCa2 )-derived CM treated cells. The numbers of $\alpha$-SMA positive cells increased significantly in TCM-exposed cells as compared to RM-exposed cells (data not shown). The morphology of the $10 \mathrm{~T} 1 / 2$ cells in the TCM groups was markedly altered to pericytes-like cells that exhibited a slender, bipolar morphology with cellular processes.
To confirm the immunofluorescence staining results, we have determined the status of the $\alpha \mathrm{SM}$-actin and desmin protein level in $10 \mathrm{~T} 1 / 2$ cells following incubation with different cell-derived conditioned media for 24 $h$. We found significant induction of $\alpha \mathrm{SM}$-actin and desmin expression in TCM exposed cells as compared to RM (Fig. 2C).

PDGF-B induces Mesenchymal-Pericyte-Transition (MPT) It is well established that tumor cells secrete different kinds of growth factors and previously we found that Platelet-derived growth factor- $\mathrm{AB} / \mathrm{BB}$ (PDGF- $\mathrm{AB} / \mathrm{BB}$ ) is one of them [20]. PDGF-AB/BB is required for maintaining the potential biological events. Since we found that human tumor cell-derived conditioned media is 


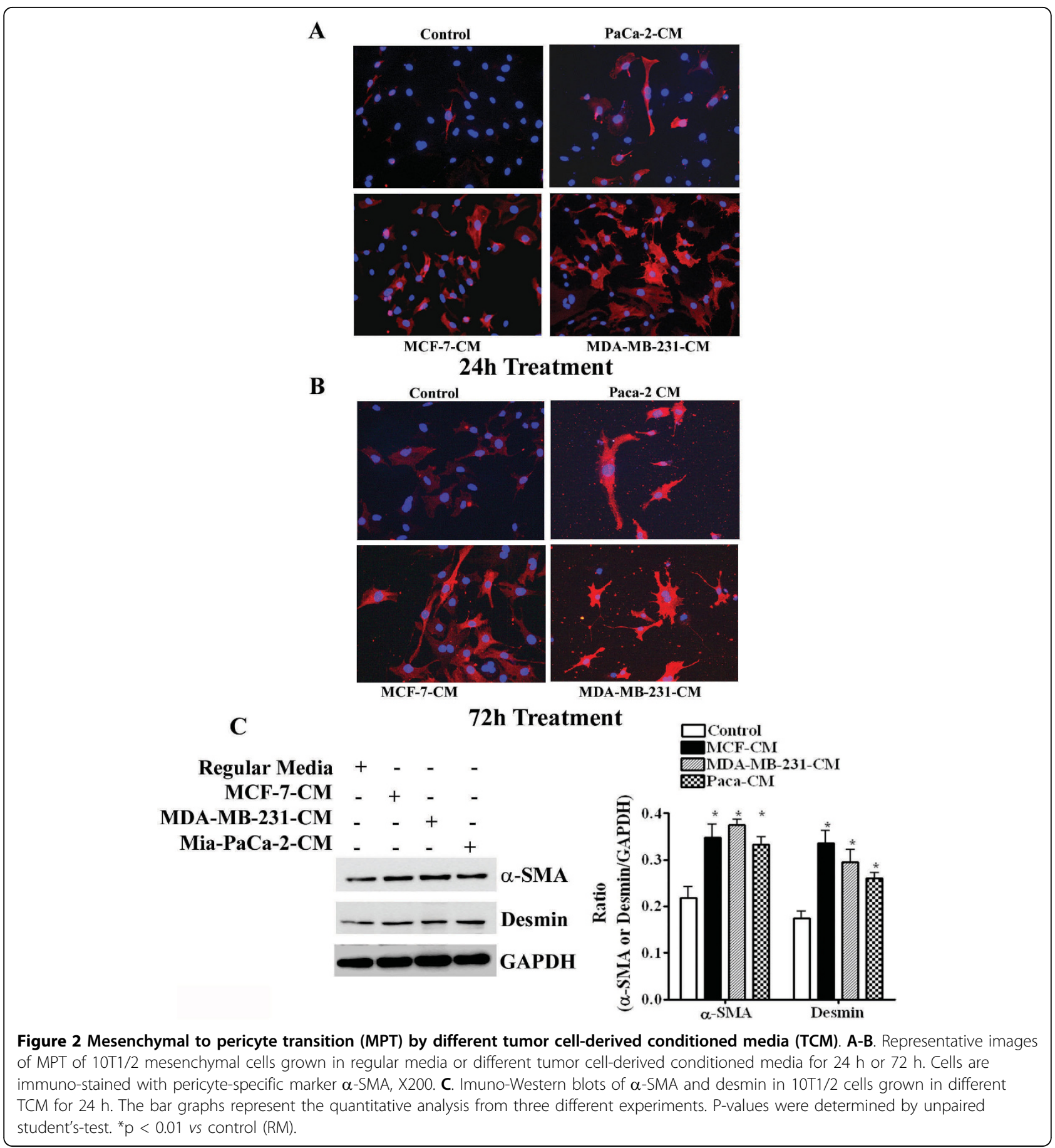

able to differentiate the mouse mesenchymal stem cells into pericytes, we investigated whether PDGF-AB/BB existed in the TCM, and is required for the mesenchymal to pericyte transition (MPT). To do so, first, we neutralized the MDA-MB-231-TCM with polyclonal rabbit anti-PDGF-BB antibody $(500 \mathrm{ng} / \mathrm{ml})$ or rabbit anti-IgG (negative control) and determined the status of $\alpha$-SM-actin using Western blot analysis. The expression level of the protein in neutralized samples was significantly reduced by 2.73 -fold as compared to negative controls (Fig. 3A). Next, we determined the morphological alterations as well as $\alpha$-SM-actin expression using an immunoefluorescence assay. To examine this, $\sim 60 \%$ confluent $10 \mathrm{~T} 1 / 2$ cells were incubated with or without recombinant PDGF-BB $(50 \mathrm{ng} / \mathrm{ml})$ at three different times and cells were fixed with ethanol. The cells 
A

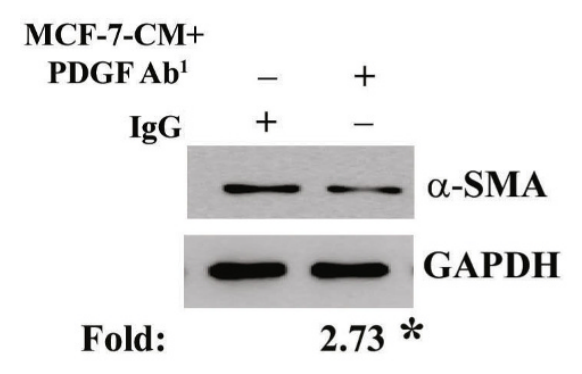

B
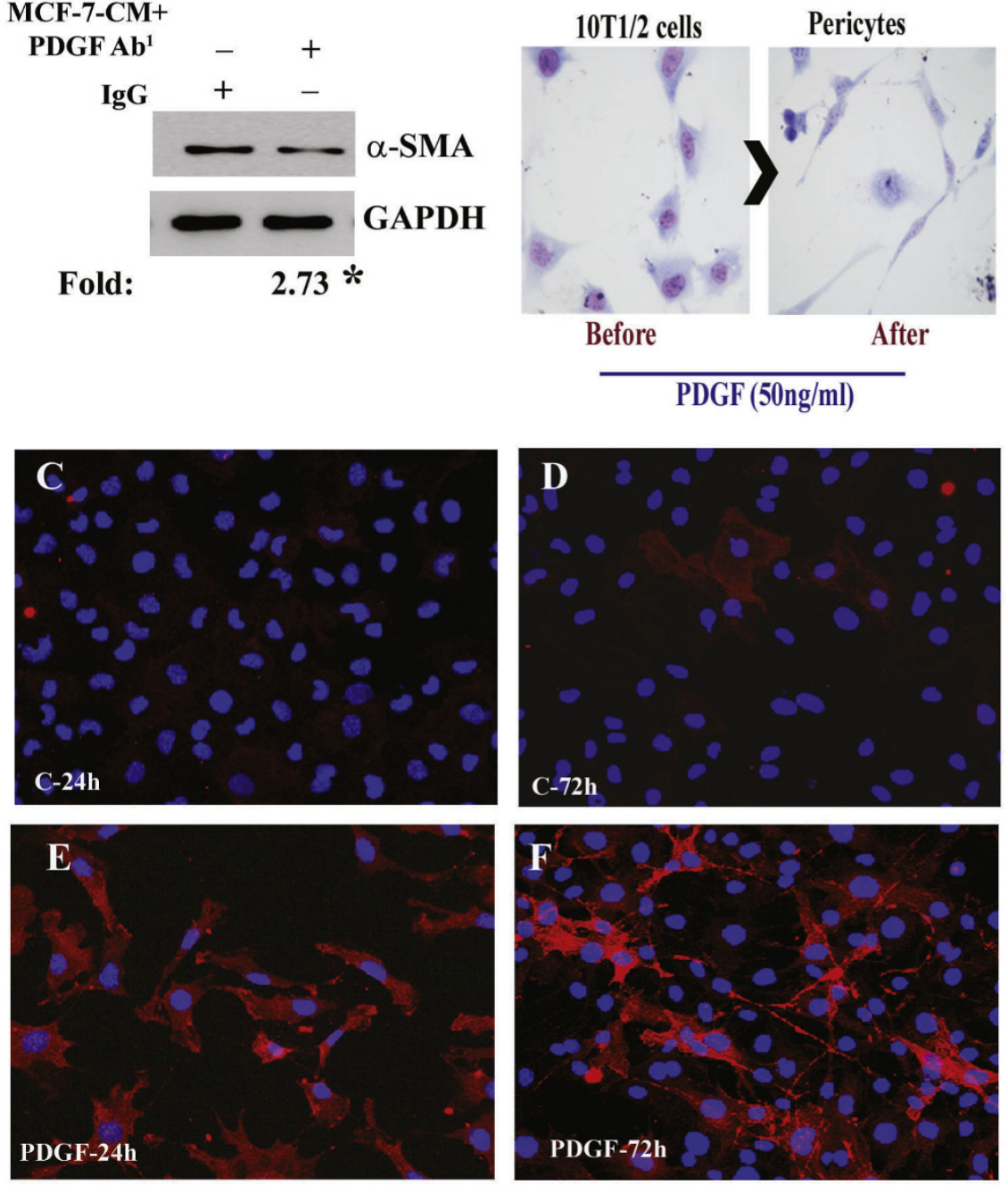

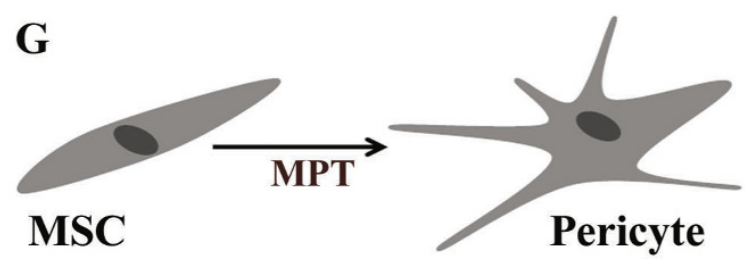

Figure 3 Tumor cell secreted PDGF-B is involved in MPT induced by tumor cells. A. Representative immuno-Western blot image illustrates the effect of PDGF neutralizing antibody on MCF-7-CM-induced $\alpha$-SMA expression in 10T1/2 cells. B. Representative Giemsa stained Photographs show that mouse mesenchymal stem cells are converted into pericytes by PDGF recombinant protein after $72 \mathrm{~h}$ treatment. C-F. Representative immunofluorescence images exhibit MPT and $\alpha$-SMA expression in PDGF-B exposed 10T1/2 cells. G. G. Schematic illustration of mesenchymal stem cell into pericyte transition.

treated for $72 \mathrm{~h}$, were stained with Giemsa solution for morphological studies, which illustrated a differentiation of fibroblast-like structures into thread-like cells (Fig. $3 \mathrm{~B})$. The cells treated for 24 and $72 \mathrm{~h}$ were also processed for immunofluorescence staining for $\alpha$-SM-actin to confirm the morphological and molecular changes, respectively (Fig. 3C-3F). The level of $\alpha$-SM-actin protein was increased in treated cells in a time dependent fashion. The morphological changes can also be seen in fluorescence stained cells. Collectively, the studies indicate that the transition from MSC to PC can be accomplished by PDGF-BB (Fig. 3B-3G). 


\section{NRP-1 is required for PDGF-B-induced MPT}

Previous studies have manifested a physical interaction of PDGF-BB with NRP-1 for vascular SMC motility for angiogenesis [20]. The objective of this work was to evaluate whether NRP-1 is required for PDGF-BB mediated MPT. To do so, first, we determined the status of NRP-1 in TCM exposed and unexposed 10T1/2 cells. NRP-1 expression was minimally detected in the cell lysate $(30 \mu \mathrm{g})$ of $10 \mathrm{~T} 1 / 2$ cells, but its expression was markedly elevated in MCF-7CM-exposed 10T1/2 cells (Fig. 4A). Next, we determined the impact of the PDGF-BB recombinant protein on MPT through the detection of tumor blood vessel-pericyte markers, such as Desmin and $\alpha$-SMA $[15,16]$. As expected, PDGF significantly increased the expression of both markers in 10T1/2 stem cells (Fig. 4B, lane 2), and these inductions were nullified when cells were pre-exposed to NRP-1 primary antibody (Fig. 4B, lane 3). Collectively, these studies suggest that a physical interaction of PDGF-BB and NRP-1 is crucial in PDGF-BB mediated MPT.

TCM is able to recruit/attach of $10 \mathrm{~T} 1 / 2$ to a capillary-like structure in vitro through PDGF-B

In this experiment, we explored whether TCM are able to increase the recruitment/attachment of transitioned pericytes with the capillaries formed by the HUVEC. To do so, a 3 D Matrigel ${ }^{\mathrm{Tw}}$ co-culture was employed. First, HUVEC were allowed to grow on Matrigel to form a capillary-like structure in the presence of GFP-taggedAOSMC for $18 \mathrm{~h}$ and capillary formation was visualized by fluorescent microscopy. Consistent with previous work $[27,28]$, this study showed that like in vivo, the AOSMC were able to attach to the capillary-like structures under in vitro conditions (Fig. 5A). Next, we evaluated whether TCM-induced mesenchymal-pericyte transition cells are capable of attaching to the capillarylike structures in vitro. To test this, HUVEC and Q-dot labeled 10T1/2 mouse mesenchymal stem cells were seeded on the matrigel, and their associations were observed after $20 \mathrm{~h}$ when the in vitro capillary-like structures are formed. The pattern of the tube-like structure formations in various TCM is different than regular media. The number of capillary-like structures was significantly higher in TCM. Moreover, the recruitment and attachment of the newly formed TCMinduced-pericytes were significantly increased under TCM as compared to RM (Fig. $5 \mathrm{~B}$ and $5 \mathrm{C}$ ). The recruitment and attachment of pericytes vary significantly within TCM. The effect was more pronounced in MCF7 cell-derived conditioned media. Finally, we needed to determine if PDGF-BB was involved in the TCMmediated recruitment event. To do so, HUVEC and Qdot labeled 10T1/2 cells were grown on the matrigel containing RM, MCF-7-CM or PDGF-BB antibody-preexposed-MCF-7-CM for angiogenesis assay. As expected, MCF-7-CM markedly increased the in vitro capillary-like structure and the attachment of Q-dotlabeled cells as compared to RM (Fig. 5B \&5C). In contrast, PDGF-B antibody-pre-exposed-MCF-7-CM was unable to either induce capillary-like structure on matrigel or induce attachment of labeled cells to the capillaries (Figs. 5D and 5E).

TCM is able to recruit/attach of $10 T 1 / 2$ cell to the newly formed capillaries in vivo

We investigated whether TCM were able to induce tumor angiogenesis under in vivo condition. To do so,

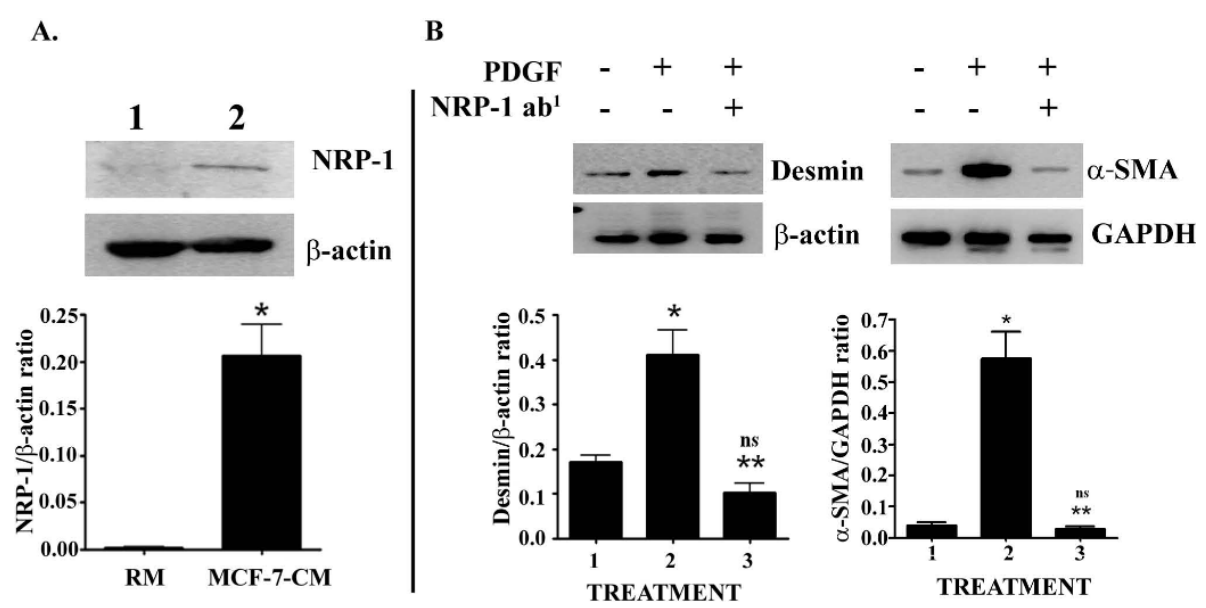

Figure 4 NRP-1 is required for PDGF-B mediated induction of $\boldsymbol{\alpha}$-SMA and desmin expression. A. Representative immuno-Western blot shows the effect of MCF-7-CM on NRP-1 expression in 10T1/2 cells. 1, RM and 2, MCF-7-CM. * $p<0.001$ vs RM. B. Detection of the effect of NRP1 antibody on PDGF-B-induced Desmin and $\alpha$-SMA expression in 10T1/2 cells. The bar graphs represent quantification of the Desmin and $\alpha$-SMA of three different experiments, P-values were determined by unpaired students't-test. ${ }^{*} p<0.001$ vs controls; ${ }^{*} p<0.001$ vs PDGF treated samples. Ns, non-significant with controls. 


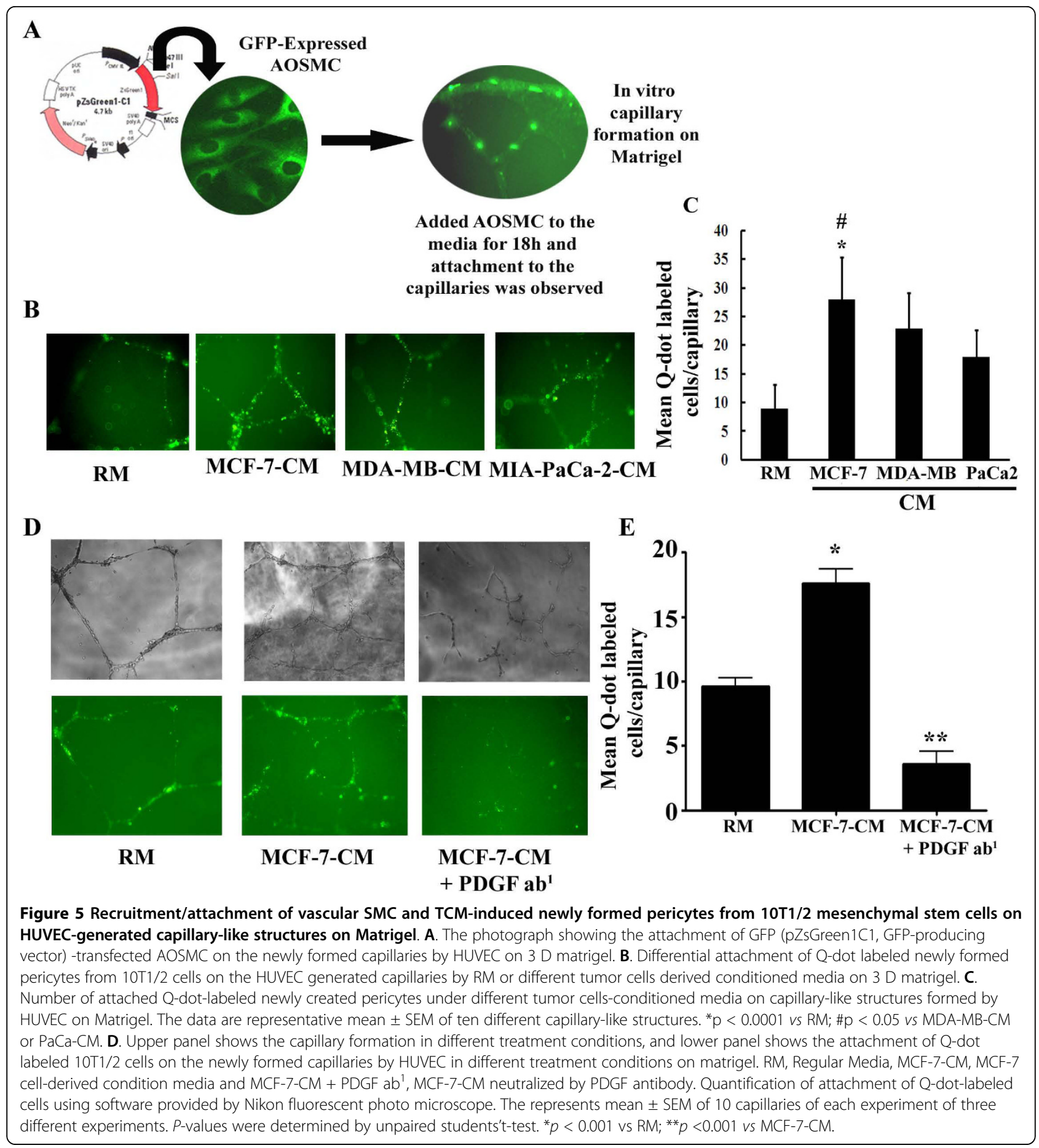

an in vivo foam-gel angiogenesis assay was performed. This assay showed that capillary formation was markedly enhanced on the MCF-7-CM-soaked gel foam as compared to water or RM soaked gel-foam (Fig. 6A). Next, we determined whether TCM promotes recruitment and attachment of 10T1/2 cells in TCM-induced newly formed blood vessels. Like in vitro, TCM significantly increased the recruitment and attachment of labeled 10T1/2 cells on newly formed blood vessels on the gel-foam (Fig. 6B).

\section{Discussion}

Differentiation of mural precursor cells to vascular SMCs/PCs and their recruitment are the fundamental 


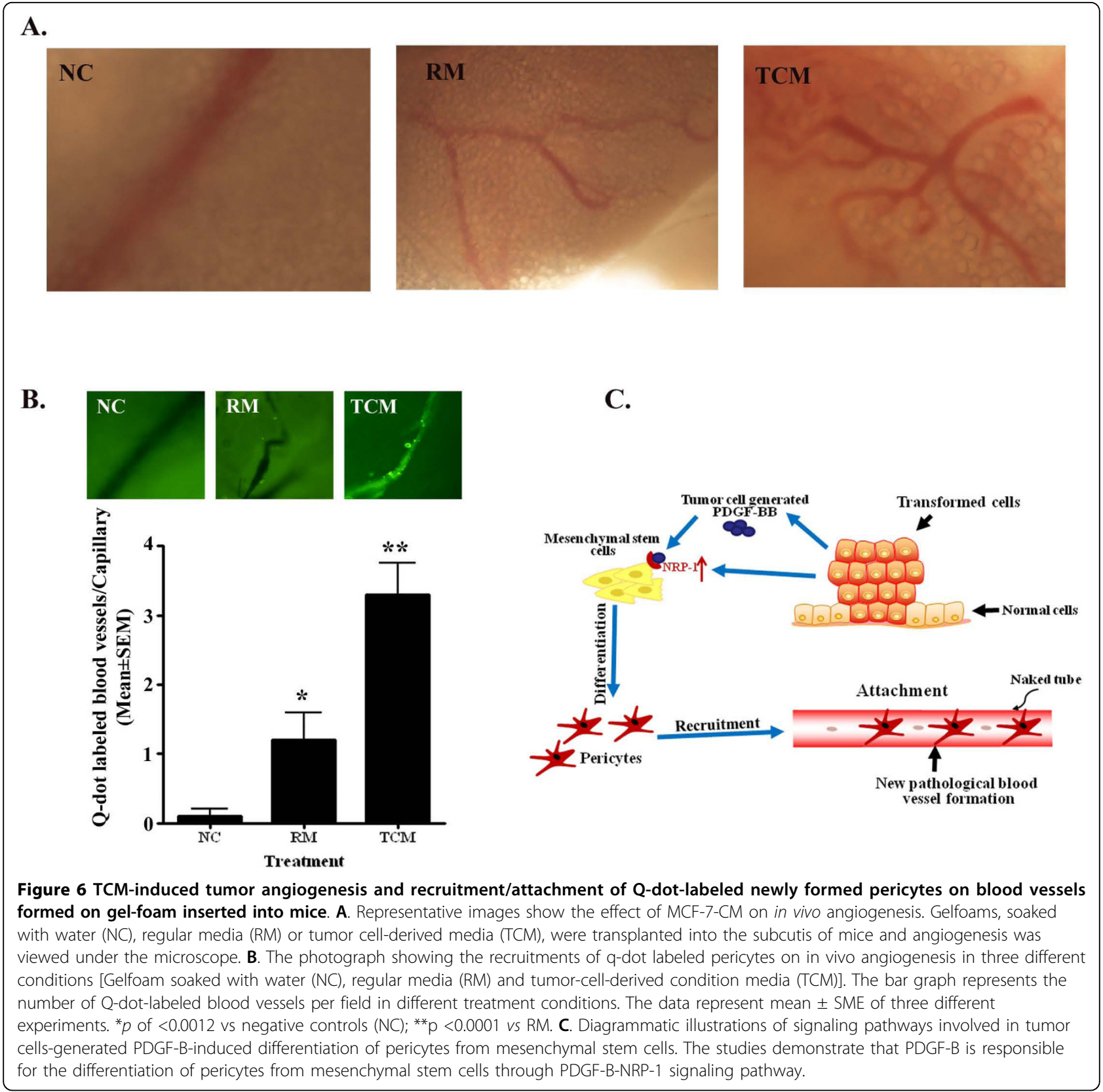

events for the maturation of both normal and tumor blood vessels created from nascent vessels [3,20,29]. One aspect that is clear from our previous studies is that tumor cells can cross-talk with vascular SMCs. The present study further described an important issue of whether tumor cells have any roles in PC biology, most specifically, enhancement of the differentiation of mesenchymal stem cells to pericytes and subsequent recruitment/attachment of PC for tumor angiogenesis through a specific molecular networking circuit.
The initial objective of the present work was to establish the working hypothesis that the interaction between tumor cells and mural precursor cells causes the differentiation of precursor cells to PCs, which ultimately proliferate and recruit to establish a mature and durable vessel. We found that when $10 \mathrm{~T} 1 / 2$ cells, $\mathrm{C} 3 \mathrm{H}$ mouse embryonic mesenchymal stem cells $(\mathrm{C} 3 \mathrm{H} / 10 \mathrm{~T} 1 / 2)$ as characterized by us and others [22] (Fig. 1), were grown in different breast and pancreatic cancer cell-conditioned media for 2-4 days, the stem cells differentiate into pericytes with abnormally high expression of 
$\alpha$-SMA along with Desmin (Fig. 2). These features are identical to the pericytes on tumor vessels $[15,16]$. Thus, we can anticipate that tumor cells have the capability to generate specific signals for mesenchymal to pericyte transitions.

Our next goal was to identified the signaling networks involved in tumor cell-induced MPT. The pericytes can originate from various cell lineages $[14,30]$ and commonly come from mesenchymal stem cells [14,31]. There are two important molecular signaling pathways that are involved in the development of pericytes [32], TGF- $\beta$ and PDGF-B signaling pathways $[14,33,34]$. Previous studies have shown that embryonic stem cells are able to differentiate into endothelial cells if they are exposed to VEGF, while they can be differentiated into pericytes in presence of PDGF-B [35-37]. In our in vitro model, we found that tumor cell-secreted PDGF-B plays a critical role in MPT (Figs.3 and 4). Most importantly, we found that the tumor cell-secreted PDGF-B-induced MPT event is mediated through NRP-1 (neuroplin-1), which is a co-receptor for semaphorins with key roles in axon guidance, a docking receptor for $\mathrm{VEGF}_{165}[38,39]$ and exhibits a physical interaction with PDGF-B in vascular SMC to enhance their migration $[20,38]$.

One of the key steps of the termination of angiogenesis is the incorporation of pericytes/vascular SMCs into the newly formed vessels $[13,40,41]$. We explored if tumor cells can enhance the recruitment and incorporation of pericytes into the newly formed endothelial tubes under in vitro and in vivo setups. The studies showed that in addition to induction of MPT, the tumor cell-generated signals including PDGF-B are able to increase the recruitment and attachment of newly differentiated pericytes into the blood vessels (Figs. 5 and 6). However, the impact of different tumor cell lines that cause pericytes to attach to blood vessels is different. Less aggressive cell lines, such as MCF-7 non-invasive breast tumor cell-generated CM caused more abundant recruitment/attachment of pericytes to the blood vessels as compared to aggressive cell lines (i.e., MDA-MB-231 and MIA-PaCa-2)-generated CM (Fig. 5). Recent studies reveal that pericytes limit metastatic spread in pancreatic $\beta$-islet cell tumorigenesis in PDGFRb ${ }^{\text {ret/ret }}$ mice [42] and in patients with colorectal cancer [43]. In agreement with these findings, less abundant recruitment of pericytes by aggressive tumor cell-CM may correlate with metastatic spread of these cells. Because MCF-7, MDAMB-231 and MIA-PaCa-2 cells highly expressed PDGF$B$ but the $C M$ of later two tumor cell lines were unable to facilitate pericytes to attach more abundantly to the capillary-like structures as compared to MCF-7-CM, these studies indicate that some additional factor(s) is essential for proper adhesion of pericytes to the vessels, which is either missing or inhibited by aggressive cancer cells for metastatic spread. Further studies are warranted. Finally, the studies also show that PDGF-B signaling not only influences MPT and recruitment of pericytes but also affects in vitro capillary stability by unknown mechanisms (Fig. 5D, last panel).

\section{Conclusions}

In conclusion, this work, as depicted in Fig. 6C, provides direct evidence that tumor cells enhance the mesenchymal to pericyte transition event for the recruitment and adhesion of pericytes on newly formed blood vessels to terminate the tumor angiogenesis process. These multistep events are apparently mediated by tumor cellsecreted PDGF-B signaling molecule. NRP-1 may play a critical role in this event. We anticipate a direct link between the disparity in recruitment of pericytes by various tumor cells and their metastatic potency. In support of this study, targeting tumor cell-secreted PDGF-B or NRP-1 in pericytes by inhibitors may efficiently diminish the tumor angiogenesis, tumor growth and metastatic spread.

\section{Materials and methods \\ Cell culture}

The mouse embryonic mesenchymal stem cells, C3H/ 10T1/2, non-invasive breast tumor cells MCF-7, T-47 D and ZR-75-1, invasive breast cancer cells MDA-MB231and invasive pancreatic carcinoma cells MIA-PaCa-2, were obtained from American Type Culture Collection (ATCC, Manassas, VA) and grown in Dulbecco's modified Eagle's medium (DMEM, Sigma Chemical Co, St. Louis, MO) supplemented with $10 \%$ fetal calf serum and antibiotics, in a humidified incubator at $37^{\circ} \mathrm{C}$ in an atmosphere containing $5 \% \mathrm{CO}_{2}$ and $95 \% \mathrm{O}_{2}$. Human aortic smooth muscle cells (AOSMC) and HUVEC (human umbilical vein endothelial cells) were purchased from Cambrex and grown in smooth muscle cells basal media $(\mathrm{SmBM})$ with various growth factors (SmGM-2, i. e., insulin, FGF, EGF and 2\% serum) and EGM-2 bullet kit (EBM-2, the basal medium supplemented with growth factors and $5 \%$ serum) respectively.

\section{Animals}

FVB/N mice (6-8 weeks of age), purchased from Taconic (Hudson, NY) were housed in autoclaved cages fitted with high efficiency filter-tops and with autoclaved bedding. The animals were fed irradiated Purina chow. The room was kept at $25^{\circ} \mathrm{C}$ with a 12-h light-dark cycle. The animal studies were carried out as per the guidelines established in the Guide for the Care and Use of 
Laboratory Animals, US Department of Health and Human Resources (NIH 1985) and VA Animal Care facilities.

\section{Reagents}

B-forms of PDGF protein and Giemsa were purchased from Sigma Chemical Co. Polyclonal rabbit anti-PDGF$\mathrm{BB}$, mouse monoclonal alpha smooth muscle-actin and Desmin antibodies were purchased from abCam (Cambridge, MA). Goat-anti mouse E-cadherin and $\beta$-Catenin and Goat-anti mouse Cytokeratin-19 and Vimentin were obtained from BD Transduction and Labvision (Neomarker) respectively. A Qtracker cell labeling kit was purchased from Invitrogen (Molecular Probes, Eugene, Oregon). Matrigel was purchased from BD Biosciences.

\section{Preparation of tumor cell-Conditioned Media (TCM)}

The procedure of preparation was the same as previously described [20]. Briefly, MCF-7, MDA-MB-231 and MIA-PaCa-2 cells were grown in DMEM media for 24 hours and collected. They were centrifuged for 10 min at $2000 \mathrm{rpm}$ at $4^{\circ} \mathrm{C}$ to remove the cells or cell debris. After, centrifugation, media were collected and used for the experiments.

\section{Cell Count}

$\sim 70 \%$ confluent $10 \mathrm{~T} 1 / 2$ cells were incubated with different tumor cell-derived condition media for 24 hours. Cells were trypsinized after 24 hours and stained with trypan blue for the count in Cellometer Auto T4 (Nexcelom Bioscience, Lawrence, MA 01843).

\section{Immunofluorescence}

Briefly, $\sim 60 \% 10 \mathrm{~T} 1 / 2$ confluent cells that were grown in a one-well slide chamber were incubated with or without PDGF-BB (Platelet-derived growth factor-BB) or different tumor conditioned media (MCF-7, MDA-MB-231 and MIA-PaCa-2) for 24 and 72 hours at $37^{\circ} \mathrm{C}$ and fixed with methanol. The slides were then permeabilized with Triton-X-100 and incubated with blocking solution (Histostain kit, Zymed Laboratories, CA) for $10 \mathrm{mins}$ at room temperature, and cells were reacted with mouse monoclonal alpha smooth muscle actin antibody overnight at $4^{\circ} \mathrm{C}$. After being washed with PBS, the cells were incubated with goat anti-mouse IgG fluorescent conjugated secondary antibody for an hour at room temperature (1:1000 dilutions, Alexa Fluor 594, Molecular Probes). Finally, the washed cells were mounted in PBS-glycerin and examined under a fluorescent microscope.

\section{Western blot analysis}

The Western blot analysis was performed in cell lysates treated with different cells derived conditioned medium according to the method described previously [20]. Cell lysates were obtained by adding lysis buffer containing $50 \mathrm{mM}$ Tris-Cl, pH-8.0, 0.1\% SDS, $150 \mathrm{mM} \mathrm{NaCl}, 1 \%$ Nonidet P-40 and protease inhibitor cocktail including 1 $\mu \mathrm{g} / \mathrm{ml}$ of Aprotinin, $1 \mu \mathrm{g} / \mathrm{ml}$ leupepsin and $1 \mathrm{mM} \mathrm{PMSF}$ and centrifuged at $4^{\circ} \mathrm{C}$. The supernatants were collected and protein concentrations were measured with coomassie blue reagent assay (Bio-Rad, Richmond, CA). Equal amounts of protein $(10 \mu \mathrm{g})$ were subjected to 7.5 - 10\% SDS-PAGE and blotted onto a nitrocellulose membrane. Membranes were incubated with specific antibodies anti-mouse monoclonal smooth muscle actin overnight and HRP-conjugated secondary antibodies were incubated for $30 \mathrm{~min}$ at room temperature. Signals were detected with Super Signal Ultra Chemiluminescent substrate (Pierce, Rockford, IL) by using ID Image Analysis software Version 3.6 (Eastman Kodak Company, Rochester, NY).

\section{Neutralization assay}

To determine the identity of the growth factor in the tumor cell-derived condition media that were mediating the conversion of stem cells into PCs, the media, conditioned by semi-confluent MCF-7, MDA-MB-231 and MIA-PaCa- 2 cells, were preincubated overnight at $4^{\circ} \mathrm{C}$ with different concentrations (i.e., 200 and $500 \mathrm{ng} / \mathrm{ml}$ ) of a neutralizing polyclonal antibody against PDGF-BB. The semi confluent mesenchymal stem cells, $10 \mathrm{~T} 1 / 2$, were then incubated with regular medium (as a control), tumor cell-derived conditioned media, neutralizing media [tumor cell-derived condition media (CM) neutralized with anti-PDGF-BB antibody and rabbit polyclonal IgG (as a negative control)] for 24 hours at $37^{\circ} \mathrm{C}$. After that, cell lysates were collected to perform the Western blot analysis for the detection of the expression level of anti-smooth muscle actin.

\section{In vitro angiogenesis and Binding assay}

Approximately $80 \%$ confluent $10 \mathrm{~T} 1 / 2$ cells were labeled with Qtracker cell labeling kit (highly fluorescent Q-dot nanocrystals) obtained from Invitrogen (Molecular Probes). For 3 D cultures, which has been described earlier [44], Matrigel $(150 \mu \mathrm{l})$ was polymerized in an 8-well chambered slide. After polymerization, endothelial cellspecific media or tumor cell-generated conditioned media were added. HUVEC and labeled 10T1/2 cells $(10,000$ cells/well) were seeded into each well and incubated for approximately $20 \mathrm{~h}$ which determined the binding efficiency of $10 \mathrm{~T} 1 / 2$ cells with capillary-like structure generated by HUVEC in regular media or different tumor cell-derived condition media. Quantification of the number of capillary-like structures and attached Q-dots were carried out using the NIS Elements software program attached with the Nikon photographic fluorescence microscope. 


\section{In vivo Angiogenesis Assay}

The Gelfoam-implantation angiogenesis assay was performed according to the previous method [45,46]. Briefly, three sets of $\mathrm{FVB} / \mathrm{N}$ mice (6-8 weeks old; four in each set) were anesthetized immediately before implantation of Gelfoam (Gelfoam ${ }^{\circ}$, Pharmacia \& Upjohn Company, NY, USA). Gelfoam $(8 \times 8 \mathrm{~mm})$, presoaked with autoclaved water, regular media or TCM, was transplanted subcutaneously in mice. The transplanted mice were maintained for 5-6 days. In the mean time, Q-dot labeled $10 \mathrm{~T} 1 / 2$ cells were cultured in regular media or TCM. After a maintenance period, labeled $10 \mathrm{~T} 1 / 2$ cells $\left(2 \times 10^{5}\right)$ were injected subcutaneously near implanted Gelfoam according to the experimental set-up. The implanted Gelfoam was taken out carefully after 2 days, and the angiogenesis was detected and quantified using an inverted fluorescence microscope. The protocol has been depicted in Additional file 1: Fig. S1.

\section{Statistical Analysis}

All experiments were performed in triplicate for each of the observations. Each of the data represents the mean \pm SE from the three separate experiments. Statistical analysis was performed between the two groups of data by an unpaired Student's $t$-test. A $P$-value less than 0.05 were considered as statistically significant.

\section{Additional material}

Additional file 1: Figure S1 - Diagrammatic illustration of Gelfoamimplantation angiogenesis assay. FVB/ $\mathrm{N}$ mice (6-8 weeks old; four in each set) were anesthetized with Ketamine HCL $(100 \mathrm{mg} / \mathrm{ml} / \mathrm{kg})$ and Xylazine $(20 \mathrm{mg} / \mathrm{ml} / \mathrm{kg})$ immediately before implantation of Gelfoam (Gelfoam ${ }^{\oplus}$ Pharmacia \& Upjohn Company, NY, USA). Gelfoam was cut into small Pieces $(8 \times 8 \mathrm{~mm})$, presoaked with autoclaved water, regular media or Tumor cell-conditioned media (TCM). Presoaked Gelfoam was transplanted subcutaneously on left or right flank of mice. The transplanted mice were maintained for 5-6 days. In the mean time, Qdot labeled 10T1/2 cells were cultured in regular media or TCM. After maintenance period, labeled 10T1/2 cells $\left(2 \times 10^{5}\right)$ were injected subcutaneously near implanted Gelfoam according to the experimental set-up. The implanted Gelfoam was taken out carefully after 2 days and the angiogenesis was detected and quantified using inverted fluorescence microscope.

\section{Acknowledgements}

We would like to thank Dr. Suman Kambhampati, MD and other CRU members for valuable suggestions on technical issues and helpful comments on this manuscript. This work was supported by Merit review grant from the Department of Veterans Affairs (SB and SKB)

\section{Author details}

${ }^{1}$ Cancer Research Unit, VA Medical Center, 4801 Linwood Blvd, Kansas City, Missouri 64128 , USA. ${ }^{2}$ Division of Hematology and Oncology, 2330 Shawnee Mission Pkwy, Westwood, Kansas 66205, USA. ${ }^{3}$ Department of Anatomy and Cell Biology, University of Kansas Medical Center, 3901 Rainbow Blvd, Kansas City, Kansas 66160, USA.

\section{Authors' contributions}

$K D, S K B$ and $S B$ initiated the project and designed the study. KD and GD performed all the treatments and the immunofluorescence. $K D, M M, I H$ and SM mainly were involved in western blot analysis. KD has assisted with the in vitro angiogenesis assay. $\mathrm{IH}$ with the help of SM performed the in vivo angiogenesis assay. All authors helped in discussing, reading and proofreading the final manuscript.

\section{Competing interests}

The authors declare that they have no competing interests.

Received: 20 May 2010 Accepted: 5 August 2010

Published: 5 August 2010

\section{References}

1. Risau W: Mechanisms of angiogenesis. Nature 1997, 386:671-674.

2. Carmeliet $P$, Jain RK: Angiogenesis in cancer and other diseases. Nature 2000, 407:249-257.

3. Carmeliet P: Angiogenesis in health and disease. Nat Med 2003, 9:653-660.

4. Folkman J: Angiogenesis and angiogenesis inhibition: an overview. EXS 1997, 79:1-8.

5. Doll JA, Reiher FK, Crawford SE, Pins MR, Campbell SC, Bouck NP: Thrombospondin-1, vascular endothelial growth factor and fibroblast growth factor-2 are key functional regulators of angiogenesis in the prostate. Prostate 2001, 49:293-305.

6. Folkman J, Klagsbrun M: Angiogenic factors. Science 1987, 235:442-447.

7. Majesky MW, Lindner V, Twardzik DR, Schwartz SM, Reidy MA: Production of transforming growth factor beta 1 during repair of arterial injury. $J$ Clin Invest 1991, 88:904-910.

8. Miyagawa J, Higashiyama S, Kawata S, Inui Y, Tamura S, Yamamoto K, Nishida M, Nakamura T, Yamashita S, Matsuzawa Y: Localization of heparinbinding EGF-like growth factor in the smooth muscle cells and macrophages of human atherosclerotic plaques. J Clin Invest 1995, 95:404-411.

9. Kato $\mathrm{S}$, Endoh H, Masuhiro Y, Kitamoto T, Uchiyama S, Sasaki H, Masushige S, Gotoh Y, Nishida E, Kawashima H: Activation of the estrogen receptor through phosphorylation by mitogen-activated protein kinase. Science 1995, 270:1491-1494.

10. Hirschi KK, Rohovsky SA, D'Amore PA: PDGF, TGF-beta, and heterotypic cell-cell interactions mediate endothelial cell-induced recruitment of 10T1/2 cells and their differentiation to a smooth muscle fate. J Cell Biol 1998, 141:805-814

11. Gerhardt $\mathrm{H}$, Betsholtz $\mathrm{C}$ : Endothelial-pericyte interactions in angiogenesis. Cell Tissue Res 2003, 314:15-23.

12. Nehls V, Denzer K, Drenckhahn D: Pericyte involvement in capillary sprouting during angiogenesis in situ. Cell Tissue Res 1992, 270:469-474.

13. Iruela-Arispe L: Endothelial cell activation. Angiogenesis: An integrative approach from science to medicine NY: SpringerFigg WD, Folkman J 2008, 35-44.

14. Bergers G: Pericytes, the mural cells of the microvascular system. Angiogenesis: An integrative approach from science to medicine NY: SpringerFigg WD, Folkman J 2008, 45-53.

15. McDonald DM: Angiogenesis and vascular remodeling in inflammation and cancer: Biology and architecture of the vasculature. Angiogenesis: An integrative approach from science to medicine NY: SpringerFigg WD, Folkman J 2008, 17-33.

16. Morikawa S, Baluk P, Kaidoh T, Haskell A, Jain RK, McDonald DM: Abnormalities in pericytes on blood vessels and endothelial sprouts in tumors. Am J Pathol 2002, 160:985-1000.

17. D'Amore PA, Shima DT: Tumor angiogenesis: a physiological process or genetically determined? Cancer Metastasis Rev 1996, 15:205-212.

18. Lindblom P, Gerhardt H, Liebner S, Abramsson A, Enge M, Hellstrom M, Backstrom G, Fredriksson S, Landegren U, Nystrom HC, Bergstrom G, Dejana E, Ostman A, Lindahl P, Betsholtz C: Endothelial PDGF-B retention is required for proper investment of pericytes in the microvessel wall. Genes Dev 2003, 17:1835-1840.

19. Guo P, Hu B, Gu W, Xu L, Wang D, Huang HJ, Cavenee WK, Cheng SY Platelet-derived growth factor-B enhances glioma angiogenesis by stimulating vascular endothelial growth factor expression in tumor 
endothelia and by promoting pericyte recruitment. Am J Pathol 2003, 162:1083-1093.

20. Banerjee S, Sengupta K, Dhar K, Mehta S, D'Amore PA, Dhar G, Banerjee SK: Breast cancer cells secreted platelet-derived growth factor-induced motility of vascular smooth muscle cells is mediated through neuropilin1. Mol Carcinog 2006, 45:871-880.

21. Banerjee S, Mehta S, Haque I, Sengupta K, Dhar K, Kambhampati S, Van Veldhuizen PJ, Banerjee SK: VEGF-A165 induces human aortic smooth muscle cell migration by activating neuropilin-1-VEGFR1-PI3K axis. Biochemistry 2008, 47:3345-3351.

22. Reznikoff CA, Brankow DW, Heidelberger C: Establishment and characterization of a cloned line of $\mathrm{C} 3 \mathrm{H}$ mouse embryo cells sensitive to postconfluence inhibition of division. Cancer Res 1973, 33:3231-3238.

23. Spaeth EL, Dembinski JL, Sasser AK, Watson K, Klopp A, Hall B, Andreeff M, Marini F: Mesenchymal stem cell transition to tumor-associated fibroblasts contributes to fibrovascular network expansion and tumor progression. PLoS One 2009, 4:e4992.

24. Jeon ES, Moon HJ, Lee MJ, Song HY, Kim YM, Cho M, Suh DS, Yoon MS, Chang CL, Jung JS, Kim JH: Cancer-derived lysophosphatidic acid stimulates differentiation of human mesenchymal stem cells to myofibroblast-like cells. Stem Cells 2008, 26:789-797.

25. Hall B, Dembinski J, Sasser AK, Studeny M, Andreeff M, Marini F: Mesenchymal stem cells in cancer: tumor-associated fibroblasts and cellbased delivery vehicles. Int J Hematol 2007, 86:8-16.

26. Hall B, Andreeff M, Marini F: The participation of mesenchymal stem cells in tumor stroma formation and their application as targeted-gene delivery vehicles. Handb Exp Pharmacol 2007, 263-283.

27. Darland DC, D'Amore PA: Cell-cell interactions in vascular development. Curr Top Dev Biol 2001, 52:107-149.

28. Hirschi KK, D'Amore PA: Pericytes in the microvasculature. Cardiovasc Res 1996, 32:687-698.

29. Jain RK, Booth MF: What brings pericytes to tumor vessels? I Clin Invest 2003, 112:1134-1136.

30. Etchevers HC, Couly G, Le Douarin NM: Morphogenesis of the branchial vascular sector. Trends Cardiovasc Med 2002, 12:299-304.

31. Creazzo TL, Godt RE, Leatherbury L, Conway SJ, Kirby ML: Role of cardiac neural crest cells in cardiovascular development. Annu Rev Physiol 1998, 60:267-286.

32. Bergers G, Song S, Meyer-Morse N, Bergsland E, Hanahan D: Benefits of targeting both pericytes and endothelial cells in the tumor vasculature with kinase inhibitors. J Clin Invest 2003, 111:1287-1295.

33. Hellstrom M, Kalen M, Lindahl P, Abramsson A, Betsholtz C: Role of PDGF-B and PDGFR-beta in recruitment of vascular smooth muscle cells and pericytes during embryonic blood vessel formation in the mouse. Development 1999, 126:3047-3055.

34. Lindahl P, Bostrom H, Karlsson L, Hellstrom M, Kalen M, Betsholtz C: Role of platelet-derived growth factors in angiogenesis and alveogenesis. Curr Top Pathol 1999, 93:27-33.

35. Yamashita J, Itoh H, Hirashima M, Ogawa M, Nishikawa S, Yurugi T, Naito M, Nakao K, Nishikawa S: Flk1-positive cells derived from embryonic stem cells serve as vascular progenitors. Nature 2000, 408:92-96.

36. Carmeliet P: Manipulating angiogenesis in medicine. J Intern Med 2004, 255:538-561.

37. Luttun A, Carmeliet P: Angiogenesis and lymphangiogenesis: highlights of the past year. Curr Opin Hematol 2004, 11:262-271.

38. Pellet-Many $\mathrm{C}$, Frankel $\mathrm{P}$, Jia $\mathrm{H}$, Zachary I: Neuropilins: structure, function and role in disease. Biochem $J$ 2008, 411:211-226.

39. Lee P, Goishi K, Davidson AJ, Mannix R, Zon L, Klagsbrun M: Neuropilin-1 is required for vascular development and is a mediator of VEGFdependent angiogenesis in zebrafish. Proc Natl Acad Sci USA 2002, 99:10470-10475.

40. Bergers $\mathrm{G}$, Song $\mathrm{S}$ : The role of pericytes in blood-vessel formation and maintenance. Neuro Oncol 2005, 7:452-464.

41. Armulik A, Abramsson A, Betsholtz C: Endothelial/pericyte interactions. Circ Res 2005, 97:512-523.

42. Xian X, Hakansson J, Stahlberg A, Lindblom P, Betsholtz C, Gerhardt H, Semb H: Pericytes limit tumor cell metastasis. J Clin Invest 2006, 116:642-651.

43. Yonenaga Y, Mori A, Onodera H, Yasuda S, Oe H, Fujimoto A, Tachibana T, Imamura M: Absence of smooth muscle actin-positive pericyte coverage of tumor vessels correlates with hematogenous metastasis and prognosis of colorectal cancer patients. Oncology 2005, 69:159-166.

44. Chodak GW, Haudenschild C, Gittes RF, Folkman J: Angiogenic activity as a marker of neoplastic and preneoplastic lesions of the human bladder. Ann Surg 1980, 192:762-771.

45. Amoh Y, Li L, Katsuoka K, Bouvet M, Hoffman RM: GFP-expressing vascularization of Gelfoam as a rapid in vivo assay of angiogenesis stimulators and inhibitors. Biotechniques 2007, 42:294, 296, 298.

46. Hayashi K, Yamauchi K, Yamamoto N, Tsuchiya H, Tomita K, Amoh Y, Hoffman RM, Bouvet M: Dual-color imaging of angiogenesis and its inhibition in bone and soft tissue sarcoma. J Surg Res 2007, 140:165-170.

doi:10.1186/1476-4598-9-209

Cite this article as: Dhar et al:: Tumor cell-derived PDGF-B potentiates mouse mesenchymal stem cells-pericytes transition and recruitment through an interaction with NRP-1. Molecular Cancer 2010 9:209.

\section{Submit your next manuscript to BioMed Central and take full advantage of:}

- Convenient online submission

- Thorough peer review

- No space constraints or color figure charges

- Immediate publication on acceptance

- Inclusion in PubMed, CAS, Scopus and Google Scholar

- Research which is freely available for redistribution

Submit your manuscript at www.biomedcentral.com/submit
C Biomed Central 